\title{
Wind and wave directional transit time model for offshore wind operation and maintenance
}

\author{
P R Mills*, B Stephen*, D McMillan*, I Lazakis ${ }^{*}$ \\ *Electronic \& Electrical Engineering University of Strathclyde, UK \{peter.mills|bruce.stephen|d.mcmillan\}@strath.ac.uk, \\ ${ }^{+}$Naval Architecture, Ocean and Marine Engineering University of Strathclyde, UK iraklis.lazakis@strath.ac.uk
}

Keywords: Offshore-wind, Access, Vessels, Maintenance, Weather-Predictions.

\begin{abstract}
Uncertainty in operation and maintenance costs of offshore renewable installations can be incurred through failure to properly account for marine conditions. One such area, vessel utilisation scheduling, requires accurate forecasts of wind and wave conditions to minimise charter costs as well as plant downtime. Additionally, fuel usage and auxiliary costs will increase with longer transfer times. Exploiting auxiliary offshore measurement data and its relation to accessibility constraints could reduce idle charter periods by allowing operatives to better anticipate prevailing site conditions. Existing models omit the effect of direction on operations and fail to account for the complex relations between dependent environmental variables which can impact on operations such as crew transfers, lifting and jacking operations. In this paper, a methodology for improving the forecasting of offshore conditions through incorporating distributed meteorological and marine observations at multiple timescales is presented Advancing towards a demonstration of a strategic maintenance approach of this kind will assist in both reducing direct costs and associated initial project finance. The developed model will be beneficial to developers and operators as better forecasting of when conditions are suitable for maintenance could reduce costs, lost earnings and improve mobilisation of vessels and technicians.
\end{abstract}

\section{Introduction}

Offshore wind is currently generating around $4 \%$ of the UK's electricity needs [1] and is expected to provide around $9 \%$ annually by 2020 [2]. With a further $19.9 \mathrm{GW}$ in construction and 5GW in planning [2]. Optimising availability is critical to national security of supply. Offshore wind turbine availabilities are of the order of $73-83 \%$ compared to onshore equivalents at $97 \%[3,4]$ incurring lower generation revenues from plant with a higher capital outlay. Operation and maintenance (O\&M) costs are significant accounting for around $30 \%$ of overall project lifetime costs [5] and of the order of £25-40 million for a typical 500MW wind farm [6], so pursuing a strategic maintenance approach will both reduce direct costs and, through increasing investor confidence, those of raising initial projects finance. Reducing the costs of initial investment is critical: if initial finance is unavailable at an economical rate, then a project cannot proceed since higher initial capital costs will increase interest rates, impacting on its economic viability. Maximising plant uptime by reducing the uncertainties in maintenance scheduling can be addressed through anticipating and understanding weather conditions better. Monitoring wave height is critical to safe access for offshore wind turbines from vessels, so identifying future time periods when access vessels cannot operate will reduce costs incurred by aborted missions. Section 2 reviews existing literature on forecasting, Section 3-4 introduces the data study site off the UK East Anglian coast. Section 5 outlines the methodology for inter-site forecasting, Section 6 present results with conclusions in Section 7.

\section{Maintenance and Forecasting}

Predicting the probability of delays to the maintenance of offshore wind turbines caused by marine conditions can inform access logistics. Possible scenarios are excessive wave heights or narrow weather windows incurred by calm periods not long enough to perform maintenance [7]. A slight improvement in vessel access capabilities can result in significant improvement in access and reductions in maintenance delays [8]. Table 1 provides example transportation access capabilities.

\begin{tabular}{|l|l|l|}
\hline $\begin{array}{l}\text { Transportation } \\
\text { means }\end{array}$ & $\begin{array}{l}\text { Max wave heights } \\
(\mathrm{m})\end{array}$ & $\begin{array}{l}\text { Max wind speed } \\
(\mathrm{m} / \mathrm{s})\end{array}$ \\
\hline CTV & 1.5 & 25 \\
SWATH* & $1.5-2$ & \\
OAV & 2 & 25 \\
Helicopter & 4 & 18 \\
Jack-up & 2.8 & 36.1 \\
Leg-stabilised & 0.5 & \\
\hline
\end{tabular}

*Small Waterplane Area Twin Hull

Table 1: Generic Maximum operating wave heights and wind speeds for a selection of transportation means $[9,10]$.

A study cites four key operations and maintenance models, some of the models use historical weather data while others use synthetically generated weather time series. Use of the same historical data for all models produced similar results, suggesting that the weather data time series used causes the biggest difference between the models [11]. ECN have developed a cost and operation and maintenance optimisation tool [12]. 
Reikard and Rogers compare statistical and physical-based models concluding that statistical models are more accurate for time horizons of less than 6 hours [13]. Therefore, this study will focus on statistical models. Hill et.al. outline a methodology for forecasting, up to 6 hours in advance. The lack of available offshore observations resulted in the use of metrologically, modelled, offshore weather data [14]. The paper uses actual data rather than synthesised observations [14-16].

Andreas and Wang analysed hourly wave height and wind speed data from 12 buoys off the North East coast of the USA over an 18 year period. The study requiring only water depth and wind speed finds a strong relation between wind speeds and wave heights with a stronger correlation at lower wave heights and wind speeds [17]. Espejo identifies a relationship between directions of wind speeds and wave heights [18]. Direction and speed can be multi-modal and there may be coupling between speed and direction. The speed or directional regimes associated with such modes indicates if it is multimodal. The analysis study splits prevailing site conditions into a number of regimens. The study concludes that the use of mixture models has the advantage over the use of Weibull distributions in that multimodal studies can be performed [19].

Gneiting et.al researches probabilistic forecasts of continuous variables; the study compares three forecasting methods; persistence, autoregressive and regime-switching space-time (RST), see section 4.5. The papers key recommendation is to improve sharpness; that is the concentration of the predicted variables. The study uses a case study of wind speeds at the Stateline wind energy centre in the US Pacific Northwest [20].

Stelle et.al provides details of wave buoy measurement for pitch and roll buoys [21]. Buoy pitch and roll are computed using angular sensors [22], see section 3.1. Distributions of directional wind speeds can be characterised using finite mixture models of continuous variable probability. Carta et.al uses a finite mixture of von Mises distributions. The research splits wind speed into cartesian components. The study concludes that mixture distributions provide a very flexible model for wind direction studies and can be used where there are several modes of prevailing wind direction [23]. This provides an analysis relevant to this research. However, the case study is in a different climatic region.

In this study, statistical models are used for forecasting less than 6 hours in advance [13]. Literature has informed key constraints on access and the selection of the constraint parameter for this study of $1.5 \mathrm{~m}$ wave heights for crew transfer [9]. Therefore, methods of forecasting when wave heights are below this threshold is investigated. The following section introduces a case study location off the UK East Anglian coast and relevant wave and wind speed data in this region.

\section{Case Study}

East Anglia One, a third development round offshore wind farm has 102 turbines rated at $7 \mathrm{MW}$ with a water depth of 30 - $42 \mathrm{~m}$. Figure 1, shows the $297 \mathrm{~km}^{2}$ area of the site which has a distance of $53.8 \mathrm{~km}$ from the shore at the centre [24]. A case study of East Anglia One Wind Farm allows modelling close to an actual site. The case study gives a real-world context and provides the potential to obtain data from developers to validate findings at a future date. This study addresses the development of a model that relates wind speeds with wave height for the selected offshore site. The closest CEFAS (Centre for Environment, Fisheries and Aquaculture Science) wave date sites are Southwold Approach (Southwold) and West Gabbard (Gabbard) as shown Figure 1 [25]. Table 2 provides the range of dates for which wave data is available for the case study site. This study uses data from the third quarter of 2012 to late 2015 to provide a fair comparison. Wind data for Gabbard is for the year of 2012 only.

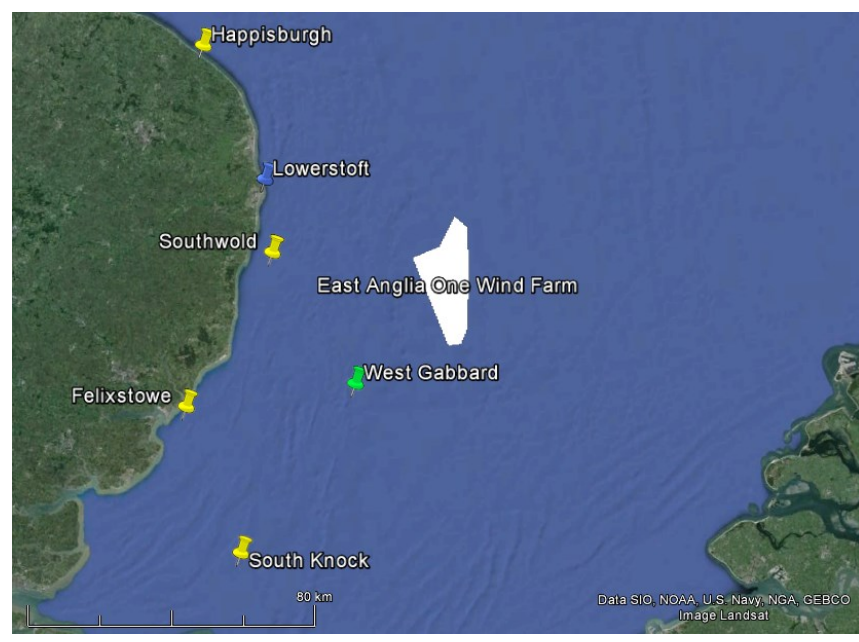

Figure 1: Case study site near East Anglia One Wind Farm

\begin{tabular}{|l|l|l|}
\hline Location & Start Date & End Date \\
\hline Happisburgh & $\mathbf{0 4 / 0 9 / 1 2}$ & $11 / 03 / 16$ \\
Southwold & $01 / 04 / 10$ & $11 / 03 / 16$ \\
Gabbard & $28 / 08 / 02$ & $11 / 03 / 16$ \\
Felixstowe & $04 / 09 / 12$ & $\mathbf{1 5} / \mathbf{1 2} / \mathbf{1 5}$ \\
South Knock & $01 / 04 / 10$ & $11 / 03 / 16$ \\
\hline
\end{tabular}

Table 2: Timescales for CEFAS data.

\subsection{Data Sources}

Waves are formed by the orbital motion of water which can be represented by frequency, amplitude, and direction. The buoy follows the orbital motion of the water as the mass of the buoy equals the of the mass of the displaced water volume. Measurement of the vertical motion of the buoy gives the wave height. For waves smaller than the buoy's circumference the motion is not followed anymore. The buoy's mooring will hinder the motion of the buoy. The mass spring resonant frequency is:

$$
\mathrm{f}_{0}=(2 \pi)^{-1}(\mathrm{C} / \mathrm{m})^{1 / 2} \text {. }
$$


where $\mathrm{C}$, in Equation (1), is the spring constant of the rubber cord in the horizontal direction and $\mathrm{m}$ is the added mass of the buoy. The buoy rides waves perfectly for wave frequencies greater than $\mathrm{f}_{0}$. For frequencies lower than $\mathrm{f}_{0}$ the buoy's horizontal motion is limited [26]. It is assumed that this is the cause of the minimum threshold for wave heights of about 0.1 $\mathrm{m}$, see Table 3 . Significant wave height is the highest onethird of waves.

\begin{tabular}{|l|l|l|}
\hline & $\begin{array}{l}\text { Min wave height recorded } \\
(\mathrm{m})\end{array}$ & $\begin{array}{l}\text { Depth } \\
(\mathrm{m})\end{array}$ \\
\hline Happisburgh & 0.09 & 10 \\
Southwold & 0.11 & 23 \\
Gabbard & 0.13 & 34 \\
Felixstowe & 0.08 & 8 \\
South Knock & 0.11 & 26 \\
\hline
\end{tabular}

Table 3: Minimum wave heights and water depth [25].

Directional buoys measure wave direction using the correlation between the buoys tilt angles and the heave motion. Pitch and roll determine the tilt angle. Morring lines can cause the direction of the buoys movement to differ from that of the waves $[21,26]$.

\section{Methodology}

Three forecasting methodologies are used in this study the first is a persistent forecast, the second and third use joint distribution to form a conditional forecast from observed data.

\subsection{Forecast Method 1 (F1): Persistence forecast}

The persistence forecast assumes conditions in three hours time will be the same as they are at the time of the forecast.

\subsection{Forecast Method 2 (F2) Conditional Gaussian forecast}

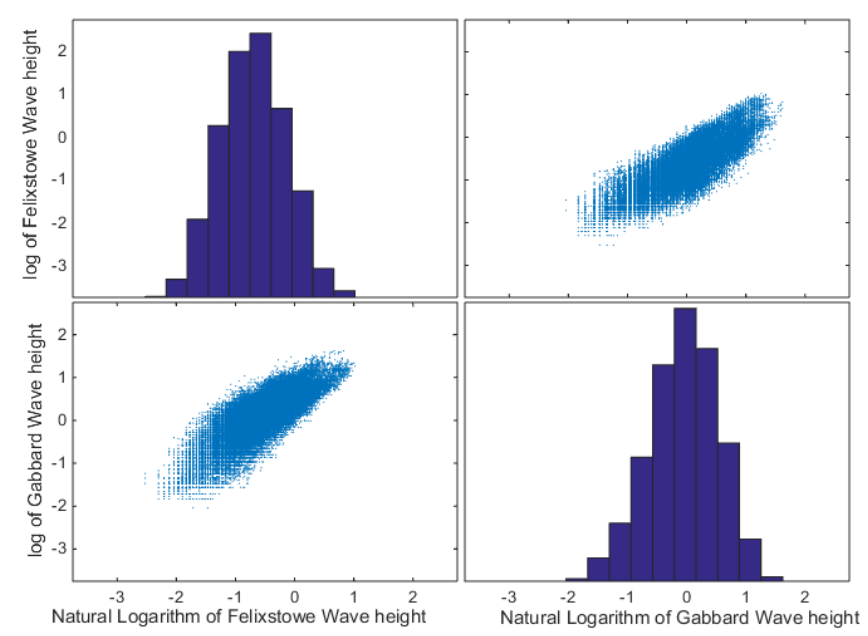

Figure 2: Log-transformed Felixstowe data demonstrating marginal Gaussian distribution characteristics.
A simple spatial correlation between two sites is performed for example wave heights at Felixstowe are used to predict wave heights at Gabbard, all forecast were for Gabbard as this is the closest of the sites to East Anglia One wind farm. Figure 2 shows the data transformed into a form more suited to use in a simple model. Log transformation of the wave data allows it to be treated as a Gaussian distributed variable, see Figure 2. The model learns the joint Gaussian distribution of the two variables and then uses the parameters to calculate the conditional form. The resulting conditional mean is used to produce the forecast.

\subsection{Forecast Method 3 (F3): Gabbard wind-wave forecast}

This method uses wind speeds at Gabbard to forecast wave heights at Gabbard. The method is the same as forecast method two except the natural logarithm of the data is not taken.

\subsection{Vessel Model}

A crew transfer vessel model has been developed based on the constraint of a maximum $1.5 \mathrm{~m}$ wave height for crew transfers [9]. The model assumes that the vessel sails if the wave height is less than or equal to $1.5 \mathrm{~m}$. For wave heights greater than $1.5 \mathrm{~m}$ the vessel does not sail. This model is run for all three forecasts and the actual data. After running this model, these four cases show the accuracy of the forecasts:

A. True positive (TP): the forecast correctly predicted that conditions were suitable.

B. True negative $(\mathrm{TN})$ : the forecast correctly predicted that conditions were not suitable.

C. False positive (FP): the forecast incorrectly predicted that conditions were suitable.

D. False negative $(\mathrm{FN})$ : the model predicted that conditions were not suitable when they actually were.

\subsection{Predictor accuracy measures}

Predictor accuracy is measured using sensitivity, specificity, Positive Predicted Value (PPV) and prevalence these are calculated using Equations (2-5) [27, 28]. Sensitivity is the number of true positives as a percentage of the actual total number of positive outcomes, see Equation (2). Sensitivity would be important for determining the probability that opportunities to do maintenance on the turbine are exploited.

$$
\text { Sensitivity }=(\mathrm{TP}) /(\mathrm{TP}+\mathrm{FN}) \text {. }
$$

Specificity is the proportion of times when the vessel cannot sail, who are correctly labelled negatively by the model, see Equation (3). Specificity would be useful for determining how likely that having got the vessel to the turbine a crew transfer can be performed. This would be especially important if crew and vessel charter are the most critical economic factors or safety considerations.

$$
\text { Specificity }=(\mathrm{TN}) /(\mathrm{TN}+\mathrm{FP}) \text {. }
$$

Positive predictive value (PPV) is the probability that given a positive result from the forecast the vessel can sail, see Equation (4). PPV provides a metric of confidence in the 
forecast; it could be useful for deciding whether to make decisions based on the forecast.

$$
\mathrm{PPV}=(\mathrm{TP}) /(\mathrm{TP}+\mathrm{FP}) \text {. }
$$

Prevalence will be the same for all forecasts for the same site regardless of the forecasting method, for the persistence forecasts it provides a comparison of the forecasts for the different locations. For the forecasts for Gabbard, it provides an additional check of the forecast results accuracy. Prevalence can be calculated from Equation (5) or directly from the data.

Prevalence $=(\mathrm{TP}+\mathrm{FN}) /($ Total Population $)$.

\section{Results}

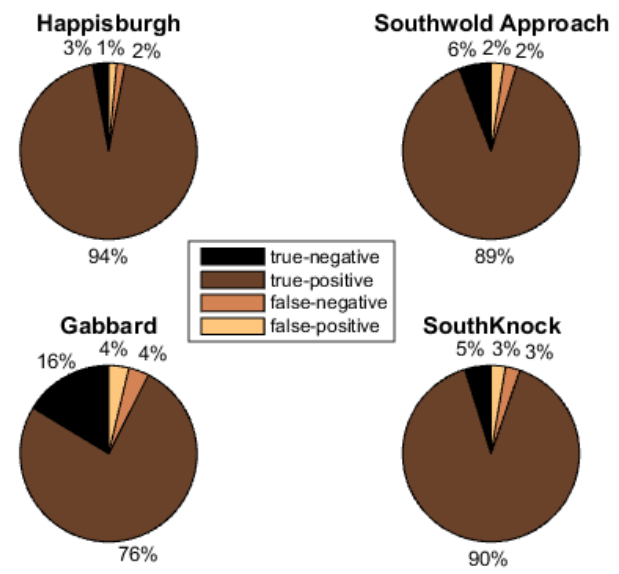

Figure 3 Persistence forecasts accuracy for sailing decisions at four sites near East Anglia One.

Each of the forecast methodologies is used with the vessel model and the prediction accuracy measures. The higher occurring true positive and true negative sectors dominate the pie charts of Figure 3, the more interesting false positive and false negative sectors are tiny making the pie charts of limited use for presenting results. Therefore, accuracy measures in section 4.5 have been used for further analysis see Figure 4, Figure 5 and Figure 6.

\subsection{Forecast Method 1 (F1): Persistence forecast}

Figure 3 suggests a relatively high accuracy of the models. However, the limited number of wave heights over $1.5 \mathrm{~m}$ means that there is a naturally greater chance of wave heights being below $1.5 \mathrm{~m}$, this applies particularly to the nearer shore sites of Happisburgh and Felixstowe. False positive and false negatives are equally likely for the persistence forecasts for all locations, due to the phase shifted nature of the forecast effectively resulting in each wave height being moved three hours into the future.

Figure 4 shows that all sites have a probability of $95 \%$ or above of correctly predicting that conditions are suitable to sail (see sensitivity). Gabbard has the highest rate of specificity that is that is Gabbard has the highest accuracy of correctly predicting when wave heights are above $1.5 \mathrm{~m}$. Felixstowe has the highest rate of PPV while Gabbard has the lowest. Some of the nearer shore sites such as Felixstowe have greater accuracy measure results possibly due to the significantly higher number of actual times when conditions are suitable to sail as shown by the prevalence. However, Gabbard is the most relevant to decisions as to whether conditions are appropriate for crew transfers to the turbine. South Knock (Knock) results are also relevant to crew transfer decisions as this is also a deeper water site, see Table 3 for a list of the water depths at the sites. The results for the near shore sites are still relevant as the vessel needs to be able to get personal safely from the harbourside to the turbine, see Table 4 for distance to shore.

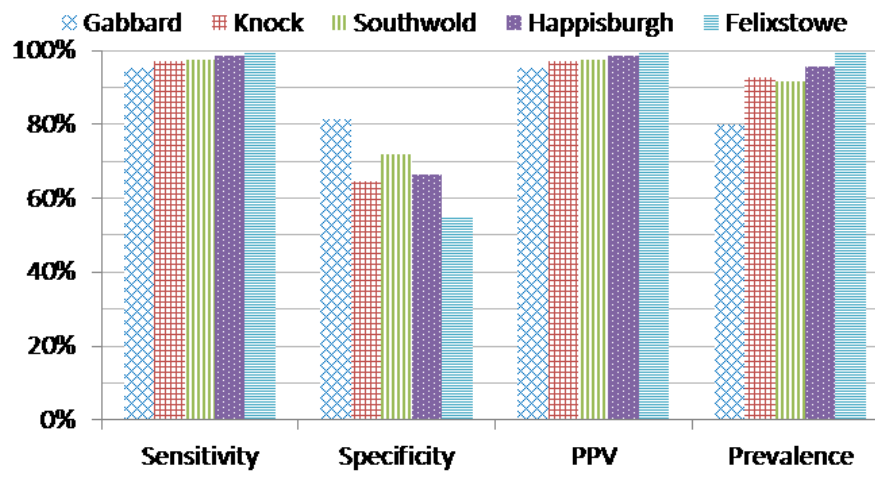

Figure 4 Comparison of accuracy measures for persistence forecasts.

\subsection{Forecast Method 2 (F2) Conditional Gaussian forecast}

Figure 5 shows a comparison of spatial models using wave heights at four sites to forecast those at Gabbard. Southwold and Felixstowe, the two closest sites to Gabbard, perform best in the conditional Gaussian forecast (F2 see section 4.2). For specificity and PPV this forecast is less accurate that the persistence forecast for Gabbard. Maximising specificity would be most important if crew and vessel charter is the deciding economic or safety factor so that the occurrences of the vessel sailing when conditions are unsuitable are minimised. PPV would be the most important factor with regards to deciding whether to use the forecast. Higher PPV shows greater confidence in the forecast. Knock and Southwold have a minimally higher sensitivity to the persistence forecast therefore on this factor alone forecast method two would be preferable however the decrease in the accuracy for the specificity and PPV metrics outweighs this marginal benefit.

For the conditional Gaussian forecast (F2) Knock and Southwold consistently perform the best these are the deeper water sites with water depths of $3 / 4$ and $2 / 3$ of the $34 \mathrm{~m}$ water depth at Gabbard it is assumed that this is the cause of the higher forecast accuracy. Happisburgh and Felixstowe are less accurate for all the metrics than the persistence forecast probably due to water depths of $10 \mathrm{~m}$ or less at these sites 
(see Table 3 for water depths). Overall, the persistence forecast (F1) for Gabbard showed higher accuracy than the F2 method. Prevalence is always $80 \%$ for Gabbard as the actual number of occurrences, when conditions are suitable to sail, is the same. Comparable water depth was found to be the most important factor in this study for determining forecast accuracy and was found to be more important than spatial distance or direction (see Table 4).

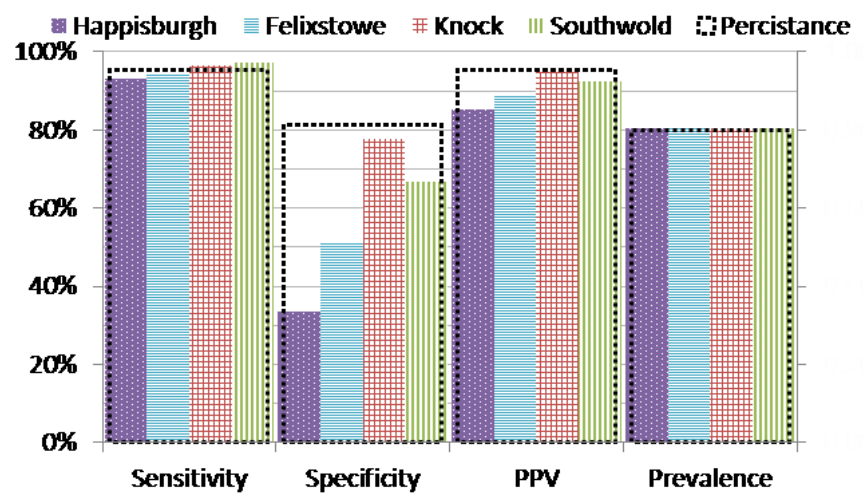

Figure 5 Comparison of accuracy measures for conditional Gaussian forecast for Gabbard wave heights (F2), dashed box, is Gabbard persistence forecast (F1).

\begin{tabular}{|l|l|l|l|}
\hline $\begin{array}{l}\text { From West } \\
\text { Gabbard: }\end{array}$ & $\begin{array}{l}\text { Distance } \\
(\mathrm{km})\end{array}$ & $\begin{array}{l}\text { Direction } \\
(\text { Deg) }\end{array}$ & $\begin{array}{l}\text { Offshore } \\
(\mathrm{km})\end{array}$ \\
\hline Happisburgh & 101 & 339 & 0 \\
Felixstowe & 47 & 226 & 4 \\
Southwold & 42 & 331 & 7 \\
Gabbard & N/A & N/A & 36 \\
Knock & 56 & 218 & 37 \\
\hline
\end{tabular}

Table 4 Distance and direction of sites from Gabbard and distance from each site to shoreline.

\subsection{Forecast Method 3 (F3): Gabbard wind-wave forecast}

The third study is conducted for the year of 2012 as Gabbard wind speed data is for this year only. Figure 6 shows predictor accuracy measures for a forecast for wave heights at Gabbard based on wind speeds at the same site; this is labelled F3 (see section 4.3). For comparison purposes, the persistence forecast for Gabbard (F1) and the spatial wave forecasts (F2) are shown. Figure 6 indicates that the forecast of wave height using Gabbard wind speed (F3) is most accurate for sensitivity. Therefore, if doing maintenance or turbine inspections as soon as possible is the priority, then this forecast may be chosen. However, this forecast is less accurate for specificity and PPV. As specificity is $56 \%$ for forecast 3 (F3), if confidence in being able to do the crew transfer on reaching the turbine is the priority then this forecast would not be used. The proportion of positive predicted values (PPV) is slightly lower for F3. Therefore, there is slightly less confidence in this forecast. The use of the F3 forecasting methodology with a truncated Gaussian distribution was investigated and was found to provide similar results. The highest wave height recorded at Gabbard in the study period was $5.1 \mathrm{~m}$. A study of data for four days either side of this outlier wave height found similar results as to Figure 6 but with a more pronounced trend. For these outlier wave heights, sensitivity was $100 \%$ for the Knock F2 forecast and $50 \%$ of the Gabbard F1 persistence forecast. For specificity, the Gabbard persistence forecast again performed best, but the Knock F2 forecast was a closer second.

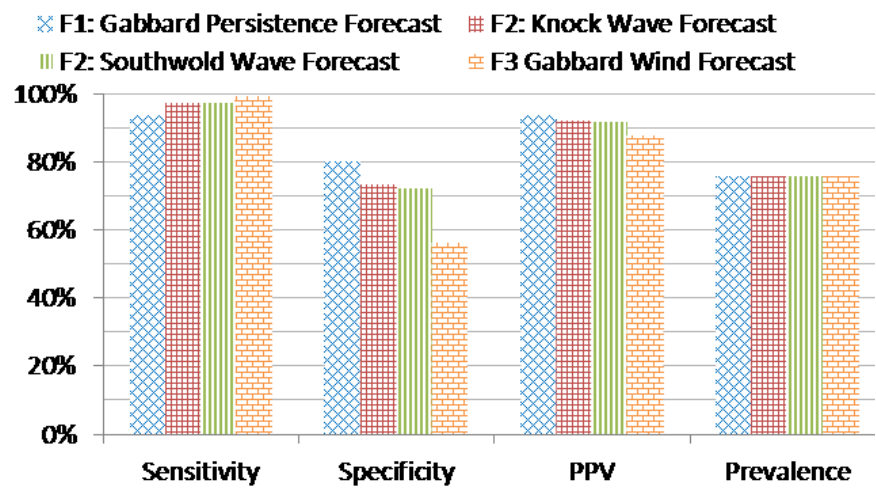

Figure 6 Comparison of forecasting methods for 2012 data.

\section{Conclusions}

The study has presented a persistent forecast and a simple forecasting model based on a Gaussian distribution. In this study, the persistence forecast showed a higher level of accuracy than a simple forecasting model based on a Gaussian distribution. However these results are for a persistence forecast for three hours in advance, for longer horizons the results may be different. The natural logarithm of wave data was taken to allow more accurate forecasting based on a Gaussian distribution. The study found that water depth was the most important factor in determining which site was most useful for forecasting wave heights at Gabbard and this was more important than spatial distance or direction. Investigating the impact of exceptional wave heights has demonstrated that the model provides similar more pronounced results in these cases. Figure 2 shows that the two natural logarithms of Felixstowe and Gabbard wave heights follow a Gaussian distribution. The scatter graphs indicate an upper tail dependency. However, the lower tails are more independent; showing a potential limitation of the forecast that while individual variables may be Gaussian distributed this does not automatically mean that they have a joint Gaussian distribution. Future work could look at the accuracy of persistence forecasts four or five hours in advance and the development of other more refined forecasting methodologies. Future work could examine the use of copulas to describe the dependence between two variables and study ways to characterise the directional dependencies between multiple sites. 


\section{Acknowledgements}

This work has been funded by the EPSRC, project reference number EP/G037728/1.

\section{References}

[1] Crown Estate. "Offshore wind energy", (2015). Available: www.thecrownestate.co.uk/energy-andinfrastructure/offshore-wind-energy/

[2] Renewable UK. "Offshore Wind", (2015). Available: www.renewableuk.com/en/renewable-energy/windenergy/offshore-wind/

[3] I. Dinwoodie and D. McMillan. "Sensitivity of Offshore Wind Turbine Operation \& Maintenance Costs to Operational Parameters", in Proceedings of the 42nd ESReDA Seminar on Risk and Reliability for Wind Energy and other Renewable Sources, (2012).

[4] I. Dinwoodie, F. Quail, and D. McMillan. "Analysis of offshore wind turbine operation and maintenance using a novel time domain meteo-ocean modeling approach", in ASME Turbo Expo 2012: Turbine Technical Conference and Exposition, pp. 847-857, (2012).

[5] I. A. Dinwoodie, D. McMillan, M. Revie, I. Lazakis, and Y. Dalgic. "Development of a combined operational and strategic decision support model for offshore wind", Energy Procedia, 35, pp. 157-166, (2013).

[6] BVG Associates. "A Guide to an Offshore Wind Farm", (2010).

[7] J. Feuchtwang and D. Infield. "Offshore wind turbine maintenance access a closed-form probabilistic method for calculating delays caused by sea-state", Wind Energy, 16, pp. 1049-1066, (2013).

[8] J. Dowell, L. Walls, A. Zitrou, and D. Infield. "Analysis of wind and wave data to assess maintenance access for offshore wind farms", in European Safety and Reliability Conference (ESREL), Amsterdam, Netherlands, (2013).

[9] Y. Dalgic, I. Lazakis, I. Dinwoodie, D. McMillan, and M. Revie. "Advanced logistics planning for offshore wind farm operation and maintenance activities", Ocean Engineering, 101, pp. 211-226, (2015).

[10] Y. Dalgic, I. Lazakis, and O. Turan. "Vessel charter rate estimation for offshore wind O\&M activities", in Developments in Maritime Transportation and Exploitation of Sea Resources, ed: CRC Press, pp. 899907 (2013).

[11] I. A. Dinwoodie, O.-E. Endrerud, M. Hofmann, R. Martin, and I. Bakken Sperstad. "Reference cases for verification of operation and maintenance simulation models for offshore wind farms", Wind Engineering, 39, pp. 1-14, (2015).

[12] L. Rademakers, H. Braam, T. Obdam, and R. Pieterman. "Operation and Maintenance Cost Estimator (OMCE)", Energy Research Centre of the Netherlands (ECN), (2014).

[13] G. Reikard and W. E. Rogers. "Forecasting ocean waves: Comparing a physics-based model with statistical models", Coastal Engineering, 58, pp. 409416, (2011).

[14] D. Hill, K. Bell, D. McMillan, and D. Infield. "A vector auto-regressive model for onshore and offshore wind synthesis incorporating meteorological model information", Advances in Science and Research, 11, pp. 35-39, (2014).

[15] COSMO. "Consortium for Small-scale Modeling" (2015). Available: www.cosmo-model.org

[16] UK Meteorological Office. "Met Office Integrated Data Archive System (MIDAS) Land and Marine Surface Stations Data (1853-current)", NCAS British Atmospheric Data Centre, (2012). Available: badc.nerc.ac.uk/view/badc.nerc.ac.uk

[17] E. L. Andreas and S. Wang. "Predicting significant wave height off the northeast coast of the United States", Ocean Engineering, 34, pp. 1328-1335, (2007).

[18] A. Espejo, R. Minguez, A. Tomas, M. Menendez, F. J. Mendez, and I. J. Losada. "Directional calibrated wind and wave reanalysis databases using instrumental data for optimal design of off-shore wind farms", in OCEANS, Santander, Spain, pp. 1-9. (2011).

[19] B. Stephen, S. Galloway, D. McMillan, L. Anderson, and G. Ault. "Statistical profiling of site wind resource speed and directional characteristics", IET Renewable Power Generation, 7, pp. 583-592, (2013).

[20] T. Gneiting, F. Balabdaoui, and A. E. Raftery. "Probabilistic forecasts, calibration and sharpness", Journal of the Royal Statistical Society: Series B (Statistical Methodology), 69, pp. 243-268, (2007).

[21] K. E. Steele, C.-C. Teng, and D. W. C. Wang. "Wave direction measurements using pitch-roll buoys", Ocean Engineering, 19, pp. 349-375, (1992).

[22] K. E. Steele, D. W. Wang, M. D. Earle, E. D. Michelena, and R. J. Dagnall. "Buoy pitch and roll computed using three angular rate sensors", Coastal Engineering, 35, pp. 123-139, (1998).

[23] J. A. Carta, C. Bueno, and P. Ramírez. "Statistical modelling of directional wind speeds using mixtures of von Mises distributions: Case study", Energy Conversion and Management, 49, pp. 897-907, (2008).

[24] 4C Offshore. "Project Details for East Anglia One", (2015). Available: www.4coffshore.com/windfarms

[25] Centre for Environment Fisheries and Aquaculture Science (CEFAS). "WaveNet" (2016). Available: www.cefas.co.uk/cefas-data-hub/wavenet/

[26] Datawell BV. "Datawell Waverider Reference Manual", Datawell BV (2009)

[27] B. D. Thombs and D. B. Rice. "Sample sizes and precision of estimates of sensitivity and specificity from primary studies on the diagnostic accuracy of depression screening tools: a survey of recently published studies", International Journal of Methods in Psychiatric Research, (2016).

[28] N. M. F. Buderer. "Statistical Methodology: I. Incorporating the Prevalence of Disease into the Sample Size Calculation for Sensitivity and Specificity", Academic Emergency Medicine, 3, pp. 895-900, (1996). 